\title{
Respect the aorta
}

\author{
Jennifer S. Lawton, MD
}

See related article on pages 145-9.

A severely atherosclerotic aorta (Figure 1) frightens most cardiac surgeons. Placement of a clamp on the heavily diseased aorta can lead to stroke or embolic events to any organ. To address the question of whether placement of 1 or 2 clamps on the aorta for coronary artery bypass surgery (CABG) reduces the risk of stroke or mortality, Araque and colleagues ${ }^{1}$ retrospectively report on 9797 patients who underwent isolated on-pump CABG between 1993 and 2010. They excluded high-risk patients (off-pump CABG, reoperative surgery, cardiogenic shock, inotrope medications, and emergency or salvage surgery), leaving a cohort of 8497 patients. Araque and colleagues ${ }^{1}$ propensity matched patients from each group (1333 matched pairs). The baseline characteristics of the patients in the 2 groups were significantly different before matching, whereas there were no significant differences between the matched cohorts. Only 1333 of 2051 patients with single clamping $(64.9 \%)$ and 1333 of 6446 patients with partial or complete double clamping $(20.6 \%)$ could be matched, suggesting inherently different patient populations to begin with.

Study end points included stroke or mortality within 30 days, and there were no differences in either unmatched or matched cohorts. Araque and colleagues ${ }^{1}$ excluded patients who required replacement of a crossclamp during the operation that was unplanned. The operations were thus surgeon specific (surgeons who routinely place 2 clamps compared with surgeons who routinely place only 1 clamp), and selection bias could be present. Most operations (76\%) were performed with 2 clamps, and the use of a partial clamp decreased every year during the course of the study.

Proponents of a single-clamp technique prefer the ability to perform proximal anastomoses without the added space constraints of a partial clamp (including reduced visibility) and the moving heart, whereas proponents of the 2-clamp

From the Division of Cardiothoracic Surgery, Department of Surgery, Washington University School of Medicine, St Louis, Mo.

Disclosures: Author has nothing to disclose with regard to commercial support.

Received for publication May 1, 2015; accepted for publication May 1, 2015.

Address for reprints: Jennifer S. Lawton, MD, Washington University School of Medicine, 660 S Euclid Ave, Campus Box 8234, St Louis, MO 63110 (E-mail: lawtonj@wustl.edu).

J Thorac Cardiovasc Surg 2015;150:150-1

$0022-5223 / \$ 36.00$

Copyright (c) 2015 by The American Association for Thoracic Surgery

http://dx.doi.org/10.1016/j.jtcvs.2015.05.002

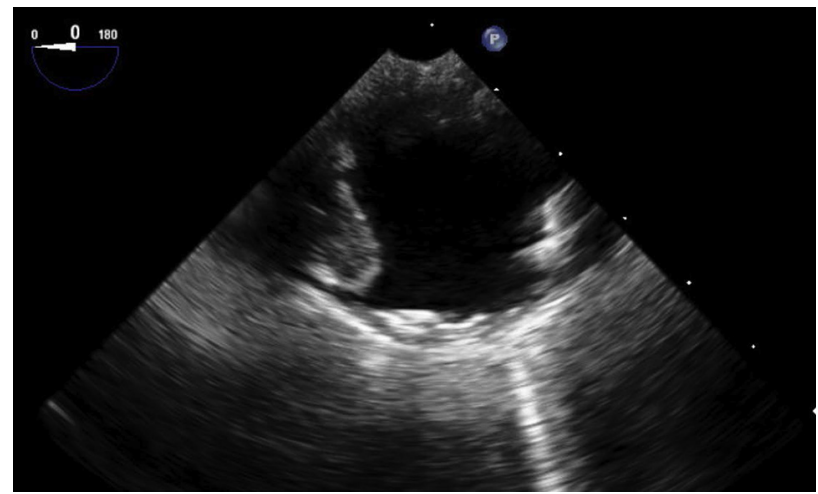

FIGURE 1. Transesophageal echocardiographic image of a diffusely diseased descending aorta.

technique prefer the ability to determine graft length with the full heart and hope to reanimate the heart as soon as possible to reduce myocardial ischemia. Interestingly, in the report of Araque and colleagues, ${ }^{1}$ the cardiopulmonary bypass time was significantly longer with the 2-clamp technique (88.2 vs 73.7 minutes), perhaps suggesting extra time needed to place and remove an additional clamp and to perform the proximal anastomoses. The crossclamp time was longer in the single-clamp group (54.5 vs 50.7 minutes). The longer clamp time did not alter the outcomes reported (stroke and mortality), although specific outcomes of myocardial injury (including need for inotropes, troponin levels, myocardial infarction, etc) were not reported. The question for the surgeon is thus, "What is more important, the brain or the heart?" weighing the risk of stroke associated with increased aortic manipulation against the risk of myocardial injury associated with prolonged clamp time.

There is no consensus in the literature to strongly advocate for either approach. ${ }^{2}$ One small randomized comparison suggested improved cognitive outcome in patients at high risk undergoing CABG with the singleclamp technique. ${ }^{3}$ A summary of randomized, controlled trials in 2008 suggested that aortic clamp strategies were equivalent in risk for postoperative stroke, although most patients were considered to be at low risk. ${ }^{4}$ Intuitively, avoidance of the aorta altogether would be the ideal strategy, and a recent retrospective report of a large patient cohort suggested that the no-touch aortic technique was associated with the lowest risk of postoperative stroke. ${ }^{5}$

The results reported by Araque and colleagues ${ }^{1}$ are valuable in that the comparison was done in a very large patient cohort ( $>8000$ patients) and that its results suggest that among the low-risk patients (those who could be matched), the use of a second clamp is not likely to 
significantly alter outcomes of stroke and mortality. Araque and colleagues ${ }^{1}$ importantly mention that a randomized study to investigate this issue would require a large number of patients in the current era because of the low risk of stroke (fortunately) in patients undergoing elective onpump CABG.

The technical choices we make as surgeons are often based on anecdotal evidence or things that we learned during training and are therefore comfortable with and wed to. Many questions remain after reading the report by Araque and colleagues, ${ }^{1}$ including the following: What is the best treatment of high-risk patients who may benefit from limited aortic manipulation the most? Can 2 clamps be safely applied to all types of aortas? Does the risk of dissection go up with the use of 2 clamps? The question of safety in all patients with either clamp approach begs for a randomized prospective trial that includes the consistent use of epiaortic ultrasonography. ${ }^{6,7}$ In the words of Michael McGonigal, "The purpose of a retrospective study is to kick us in the head, to challenge an assumption and to stimulate the design of a study that will generate class one data." 8

\section{References}

1. Araque JC, Greason KL, Li Z, Heins CN, Stulak JM, Daly RC, et al On-pump coronary artery bypass graft operation: is one crossclamp application better than two? J Thorac Cardiovasc Surg. 2015;150:145-9.

2. Daniel WT III, Kilgo P, Puskas JD, Thourani VH, Lattouf OM, Guyton RA, et al Trends in aortic clamp use during coronary artery bypass surgery: effect of aortic clamping strategies on neurologic outcomes. J Thorac Cardiovasc Surg. 2014; 147:652-7.

3. Hammon JW, Stump DA, Butterworth JF, Moody DM, Rorie K, Deal DD, et al Single crossclamp improves 6-month cognitive outcome in high-risk coronary bypass patients: the effect of reduced aortic manipulation. J Thorac Cardiovasc Surg. 2006;131:114-21.

4. Raja SG, Navaratnarajah M, Fida N, Kitchlu CS. For patients undergoing coronary artery bypass grafting at higher risk of stroke is the single cross-clamp technique of benefit in reducing the incidence of stroke? Interact Cardiovasc Thorac Surg. 2008;7:500-3.

5. Moss E, Puskas JD, Thourani VH, Kilgo P, Chen EP, Leshnower BG, et al Avoiding aortic clamping during coronary artery bypass grafting reduces postoperative stroke. J Thorac Cardiovasc Surg. 2015;149:175-80.

6. Thourani VH, Razavi SA, Nguyen TC, Kilgo PD, Puskas JD, Guyton RA et al. Incidence of postoperative stroke using the Heartstring device in 1,380 coronary artery bypass graft patients with mild to severe atherosclerosis of the ascending aorta. Ann Thorac Surg. 2014;97:2066-72; discussion 2072.

7. Bergman P, Hadjinikolaou L, van der Linden J. Aortic atheroma is related to number of particulates captured by intra-aortic filtration in CABG. Eur $J$ Cardiothorac Surg. 2002;22:539-44.

8. Schein M. Aphorisms \& quotations for the surgeon. Shrewsbury (UK): TFM Publishing; 2003:204. 